\title{
Defining a unified vascular phenotype in systemic sclerosis
}

Yannick Allanore ${ }^{1}$, Oliver Distler ${ }^{2}$, Marco Matucci-Cerinic ${ }^{3}$, Christopher Denton ${ }^{4}$

1. Department of Rheumatology A, Cochin Hospital, INSERM U1016, Paris Descartes University, Paris, France.

2. Department of Rheumatology, University Hospital Zurich, Switzerland

3. Department of Experimental and Clinical Medicine, Division of Rheumatology and Scleroderma Unit, Azienda Ospedaliera Universitaria Careggi, University of Florence, Viale Pieraccini 18, 50139, Florence, Italy

4. UCL Division of Medicine, University College London, London, UK; UCL Centre for Rheumatology and Connective Tissue Diseases, Royal Free Hospital, London, UK

\section{Corresponding author: Pr Yannick ALLANORE}

Service de Rhumatologie A, Hôpital Cochin

Université Paris Descartes

27 rue du Faubourg Saint-Jacques

75014 Paris, France

Telephone: + 33 158.41.25.63 Fax: + 33 158.41.26.24

e-mail: yannick.allanore@aphp.fr

This work did not receive any specific financial support.

\section{Disclosures :}

Prof. Y Allanore had consultancy relationship and/or has received research funding from Actelion, Bayer, Boehringer Ingelheim, ChemomAb, Genentech/Roche, Inventiva, Pfizer, Sanofi, Servier, in the area of potential treatments of scleroderma and its complications.

Prof. Dr. O. Distler had consultancy relationship and/or has received research funding from Actelion, Bayer, Boehringer Ingelheim, ChemomAb, espeRare foundation, Genentech/Roche, GSK, Inventiva, Lilly, medac, Medlmmune, Mitsubishi Tanabe Pharma, Novartis, Pfizer, Sanofi, Sinoxa and UCB in the area of potential treatments of scleroderma and its complications. In addition, Prof. Distler has a patent mir-29 for the treatment of systemic sclerosis licensed.

Prof. Denton has had consultancy relationship and/or has received research funding from Roche/Genentech, Actelion, GlaxoSmithKline, Sanofi-Aventis, Inventiva, Boehringer-Ingelheim, CSL Behring, EMD Serono, Inventiva, and UCB Pharma in the area of potential treatments of scleroderma and its complications 
Abstract:

Microcirculation impairment and related vasculopathy is a hallmark of systemic sclerosis. Digital ulcers are second only to Raynaud's phenomenon as a vascular complication occurring in scleroderma patients. Digital ulcers are painful and generate

disability. Furthermore, patients may develop recurrent digital ulcers and one may ask whether the outcomes of such patients might be different to those of unaffected ones. Recently several registries have provided relevant information about digital ulcers. Male sex and severe skin disease seem to be the main associated factors observed in several registries. However, the limitations in those studies are the differences with regards to the definitions of digital ulcers and of organ involvement. Few longitudinal studies are available and the more robust data from EUSTAR cohort suggest worse outcomes when a history of digital ulcers is present but could not demonstrate that it can predict additional vascular complications like pulmonary arterial hypertension, heart failure or renal crisis. Nevertheless, the old autopsy studies and the more recent biomarker longitudinal studies support the concept of generalized vasculopathy and a potential association between various cardiovascular complications. It is expected that with the availability of several structured registries, the question about the identification of a vascular profile, or vascular phenotype, will be addressed using more robust data in a near future.

Key-words: digital ulcer- vasculopathy- Raynaud's phenomenon- pulmonary arterial hypertension- renal crisis- heart failure 
Systemic sclerosis (SSc) is an autoimmune connective tissue disorder that is characterized by a complex interplay of vascular abnormalities, immune system activation and an uncontrolled fibrotic response. Vascular component is often referred to as vasculopathy and is seen as having a key role in the early pathogenesis of SSc. Patients with SSc develop a broad spectrum of vascular manifestations including the almost universal Raynaud's phenomenon (distal vasospasm), commonly digital ulceration and more rarely critical digital ischaemia. In parallel, within this very heterogeneous disease, some patients will develop vascular related organ damages leading to heart or kidney failure [1-3]. It is still unclear whether there is a continuum between peripheral vasculopathy promoting digital ulceration (DU), or critical ischemia, and some other vascular related complications $[4,5]$. The objective of this article is to address this question by analysing whether severe digital vasculopathy could be a surrogate for vasculopathy elsewhere. The various sources of information to answer this research question are shown on figure 1.

\section{GENERALIZED MICROVASCULAR DAMAGE: from Raynaud's to obliterated small vessels}

SSc vasculopathy depends on the complex interaction of various pathological processes including autoimmunity, impaired compensatory vasculogenesis, and angiogenesis, endothelial-mesenchymal transition (EMT), endothelial dysfunction, and impaired coagulation/fibrinolysis system. SSc vasculopathy is characterized by a variety of such changes that affect primarily the microcirculation and small arterioles [4,5]. Larger vessel disease can occur in SSc [6], although there are still some 
debates about the risk of atherosclerosis in SSc [7]. This topic is beyond the scope of our article that looks primarily at the potential risk of generalized microangiopathy and a potential continuum between digital ulcers and organ based vasculopathy.

The hallmark of functional abnormalities related to SSc vasculopathy is Raynaud's phenomenon (RP). It is characterized by exaggerated but reversible vasospasm in response to cold exposure, stress, or emotional upset. Vascular tone dysfunction is mainly due to an impaired endothelial function. Several studies have demonstrated the reduction of flow-mediated dilation values supporting an impaired nitric oxide production [8]. It must be pointed out that although it is mainly recognized at the digital level it is well established that all microcirculatory systems can be affected (heart, nose, gut) [4,5]. By example, cardiac imaging showed abnormal perfusion related to small coronary artery disturbances after cold stress [7].

With the progression of structural vascular changes, functional alteration of vascular cells includes endothelial apoptosis, impaired coagulation/fibrinolysis system, aberrant expression of soluble factors and cell adhesion molecules leading to the pathological inflammation. In this phase, perivascular infiltrates are evident, endothelial cells, pericytes and vascular smooth muscle cells proliferate, endoMT takes place and myofibroblast are activated in the dermal tissue [9]. The next steps include altered neovascularization and vascular remodelling due to the impairment of compensatory vasculogenesis and exaggerated angiogenesis [10-16]. Circulating levels of various angiogenic/angiostatic factors are largely altered and, so far, most of studies have revealed that pro-angiogenic factors are increased throughout the disease course, especially in the active stage of the disease $[17,18]$. The progression of these events leads to intima and media fibroproliferation which will provoke a microvessel obliteration. Consequently, chronic hypoxia may further 
promote the fibrosis of the surrounding tissue [16]. The early damage to the endothelium together with the vascular instability and the chronic hypoxia generating reactive oxygen species have thus a downstream deleterious effect on capillaries [17]. This leads eventually to an aberrant angiogenesis and progressively to a loss of capillaries. The vessel obliteration will further progress to tissue anoxia which will have a devastating effect on the extremities with tissue necrosis and gangrene [17]. Taken together, these findings support a generalised microvascular impairment in SSc. One may ask why the digits might be primarily affected but the exposure to cold of this body area is submitted to more important and/or earlier damages that could explain the high risk for the development of digital ischemia and ulceration. Nevertheless, the pathogenesis of the vasculopathy, the findings of abnormal circulating markers as previously highlighted, such as the inverse correlation of FMD values with pulmonary arterial pressure and the association of decreased FMD values with the presence of pulmonary arterial hypertension and digital ulcers, indicate the presence of a generalized vascular abnormality $[19,20]$. Therefore, the natural course of the disease should be evaluated more deeply to see whether the proliferative and obliterative vasculopathy may gradually and sometimes subclinically progress along with disease duration, becoming eventually clinically evident with variable tonality of severe vessel involvement. This may thus lead to the periodic or recurrent $\mathrm{DU}$, to pulmonary arterial hypertension $(\mathrm{PAH})$, to heart failure and to renal function decline or renal crisis. 


\section{RISK FACTORS AND VASCULARS COMPLICATIONS IN SSC PATIENTS HAVING DIGITAL ULCERS: DATA FROM CROSS-SECTIONAL STUDIES}

To investigate the vascular clinical manifestations occurring in patients with DU, the characteristics of SSc-DU patients versus the non-affected patients have been analysed in the report of large cross-sectional series.

In a French multicentre study, the cross-sectional analysis of 599 patients with SSc, found that $53 \%$ had prior or current DU. Looking at associated variables, DU appeared to occur more frequently among males, patients with a higher Rodnan skin score, patients with early onset of disease, patients with carbon monoxide lung diffusion capacity (DLCO) $<60 \%$ predicted, and patients with anti-topo I antibodies. It must be highlighted that sex and skin disease were the strongest associated variables. The frequency of PAH was not higher in patients with prior or current DU than in those never affected [21]. DLCO measures gas exchanges through the alveolar membrane and can be influenced by the thickness of the alveolar membrane and lung capillary volume. Therefore, a reduced DLCO in the absence of impairment in pulmonary function (FVC \%) may represent a surrogate marker of vasculopathy. The association with DLCO impairment, the worsening of RP and the presence of recurrent DU indicate the pathophysiological link between the disease involvement of two different endothelial systems, that of the lung and the digits. However, no relationship between prior or current $\mathrm{DU}$ and $\mathrm{PAH}$ was observed in Tiev et al study. The German network has provided data derived from 1880 patients from whom 1690 were evaluable for DU. Out of these, 408 (24\%) had DU at the time of entering the registry. In multivariate analysis, datasets from 1164 patients were used and revealed that male sex was the most powerful independent predictor for the presence of DU and that PAH, anti-Scl70 antibodies (but not ACA), involvement of the mouth 
or oesophagus, elevated erythrocyte sedimentation rate or onset of RP at young age were all risk factors for the presence of DU. Diffuse skin sclerosis in combination with PAH was the most powerful predictor for the occurrence of DU [22].

In another national project, a total of 19 Spanish centres participated in the recruitment of 1326 SSc patients; of these, 552 SSc patients had prior or current DU. Multivariate analysis identified that history of prior/current DU in patients with SSc was independently associated to younger age at SSc diagnosis, diffuse cutaneous SSc, peripheral vascular manifestations such RP, telangiectasia, and acro-osteolysis [23]. However, history of DU was not associated with any visceral vasculopathy such as PAH or scleroderma renal crisis.

The Canadian registry investigated the features associated with DU and their complications and made an effort to determine if DU were associated with PAH and scleroderma renal crisis (SRC). Among 938 SSc patients, $8 \%$ had a current DU, 44\% had a digital ulcer ever, and 53\% had digital pitting scars. In the multivariate analysis, the most important variables to predict DU were younger age of onset, ILD, higher hand and finger skin score, and higher HAQ score [24]. There was no significant association between the history of $\mathrm{DU}$ and any definition of PAH (prevalence measured at 9\%) and neither with renal crisis (prevalence of $5 \%$ ).

If microcirculation impairment is fundamental in SSc vasculopathy, large vessel disease may overlap and contribute to tissue sufferance, although the potential role of atherosclerosis in SSc vascular damage is still debated. A Japanese crosssectional study looked at 254 patients among whom 48 SSc patients had prior or current DU (19\%). There were no multivariable analyses performed but it is of interest to point out that carotid atherosclerosis was not more common in patients with DU as compared to SSc patients without DU. Regarding SSc characteristics, DU 
were more common in males, in DcSSs, mRSS was higher in patients with a history of DU confirming previous findings coming from other geographical populations [26]. A focus was then done on heart disease, showing no more PAH in DU-SSc patients (9 vs $10 \%$ in DU-SSc versus non-DU-SSc). After exclusion of the PAH patients, those with DU had more commonly elevated natriuretic peptide or milder cardiac abnormalities such as EKG changes or coronary artery disease [25].

Cutaneous telangiectasias are common in SSc and part of the ACR EULAR classification criteria. A cross-sectional study aimed at determining whether the number and size of cutaneous telangiectasia were associated with the pattern of microvascular lesions assessed by nailfold videocapillaroscopy (NVC) and markers reflecting the severity of SSc-related vasculopathy. Among total of 87 patients profuse and pseudotumoral cutaneous telangiectasia were both associated with capillary loss and severe dysangiogenesis on NVC [26]. In multivariate analysis, profuse pseudotumoral cutaneous were independently associated with past or current digital ulcers whereas pseudotumoral cutaneous were independently associated with the late NVC pattern and PAH [28]. Of the most interest, a previous study showed some association between telegiectasia and PAH with adjusted relative odds of $\mathrm{PAH}$ of 12 for patients with a 10-point increase in telangiectasia score [27]. These 2 studies emphasize on telangiectasia being a potential clinical marker of more widespread aberrant microvascular disease in SSc.

Regarding another vascular organ complication, there are few studies about the risk factors of renal crisis however, none did suggest so far that DU or PAH may be risk factors for such event [28].

The results of the main above studies are summarized in Table 1 where associations observed in multivariable analyses are highlighted. Altogether, with the limitation of 
their cross-sectional design, they show that DU are more common when SSc occurred earlier, in male patients, in those with DcSSc subset and high mRSS, but they do not show consistently higher risk of $\mathrm{PAH}$, heart failure or renal crisis in $\mathrm{DU}$ patients as compared to non-DU patients.

\section{VASCULARS COMPLICATIONS IN SSc PATIENTS HAVING DIGITAL ULCERS: DATA FROM LONGITUDINAL STUDIES}

Another way to explore if DU may be a surrogate for generalized vasculopathy is to look at prospective data to see whether SSc patients with DU at baseline develop more organ vasculopathy than non-affected patients.

A study looking at the natural history of SSc-DU was based on 103 patients among whom 46 had a history of DU. The mean duration of follow-up from the first nonRaynaud SSc symptoms was about 12 years. In $43 \%$ of cases, the first DU occurred within 1 year following the first non-Raynaud SSc symptoms, and within 5 years in $73 \%$ of cases. In multivariable analysis, younger patients at occurrence of first nonRaynaud SSc symptoms and with higher skin score (such has being classified with a diffuse cutaneous subset) experienced earlier DU occurrences. It must also be pointed out that the first DU manifestation was delayed when vasodilator therapy was offered (mainly calcium channel blockers or ACE inhibitors). Pulmonary arterial hypertension (PAH) occurred in 11 patients (11\%) during the course of the disease and its prevalence was comparable between the subgroups (14\% PAH in the DU subgroup and 9\% PAH in the no DU subgroup; $p=0.53$ ) [29].

One of the main studies that highlighted the link between DLCO and vasculopathy was based on Pittsburgh's Scleroderma Databank from which 106 patients who had the diagnosis of PAH were matched with 106 controls by SSc skin subtype, age, sex, 
race, disease duration, and the mean time to the diagnosis of $\mathrm{PAH}$ after the initial Pittsburgh visit. If a decline in DLCO pre-empted $\mathrm{PAH}, \mathrm{PAH}$ patients and controls had a similar frequency of $\mathrm{RP}$, digital tip ulcers, and digital gangrene. However, visual analogue scales for RP, showed that cases had significantly higher values for both the severity of RP and the severity of digital tip ulcers [30].

In EULAR Scleroderma Trials and Research (EUSTAR) EUSTAR cohort it was showed that at the first visit, 1092/3196 patients had a history of DU (34\%). Followup at 3 years was the-cut-off time to look at the occurrence of complications [31]. In multivariable analyses adjusting for age, gender and other parameters considered potentially significant, a history of DU was strongly predictive for the presence of DUs at prospective visits, but also for an elevated systolic pulmonary arterial pressure on heart ultrasound, for any cardiovascular event (new DUs, elevated echo-sPAP or left ventricular failure, and for death). Overt PAH could not be analyzed and there was no prediction for renal crisis [31].

In the Australian PAH registry, among 1636 patients with SSc, 194 (12\%) had PAH proven by right-heart catheter including 160 who were detected prospectively by screening. The study primarily looked at the outcomes of patients according to the screening programmes but the characteristics of SSc-PAH are detailed and analysed using univariate analyses. The data show that SSc patients with PAH were older, had longer disease duration from the first non- RP clinical manifestation, were more likely to be anti-centromere-positive and to have telangiectasia, calcinosis and joint contractures [32]. Furthermore, DU were more frequent in $\mathrm{PAH}$ patients $(53 \%$ in PAH-SSc patients and $42 \%$ in SSc non PAH patients) but the strength of association is not very strong and multivariable analyses would be required to determine independency in prediction. 
The German network has also looked at prospective data regarding DU and showed various progression according to SSc characteristics. Unfortunately, no details were provided for other outcomes except for a statement that the weak or lack of association of DUs with pulmonary hypertension or heart and renal involvement indicates that the vasculopathy in digital arteries and the renal and pulmonary vasculature seem to be affected by different pathophysiological pathways [33].

Conversely to the cross-sectional analyses, the available longitudinal data seem to support some links between baseline DU and the subsequent risk of more sevre vasculopathy defined by recurrent $\mathrm{DU}$ but also the risk of PAH. The low frequency of renal crisis and heart failure limits the possibility to identify such links but the large EUSTAR registry supports a predictive value of baseline DU for overall cardiovascular complications. Confirmation will have to be investigated in new extracts with more patients and longer follow-up.

\section{VASCULAR BIOMARKER STUDIES}

Many studies investigated in recent years candidate vascular biomarkers. While some were mainly descriptive using cross-sectional design, some others were based on longitudinal data allowing prediction of overall vascular risk [34].

The pentraxins are a very conserved family of proteins with a unique architecture. In humans the two main members of this family are C-reactive protein and serum amyloid P. Pentraxin 3 (PTX3) is expressed predominantly in atherosclerotic lesions that involve various cells such as macrophages, neutrophils, dendritic cells, or smooth muscle cells. Interestingly, PTX3 has been examined, as a novel biomarker for inflammatory cardiovascular disease. In SSc, circulating PTX3, but also fibroblast growth factor 2 (FGF-2) levels, have been found to be significantly higher in SSc 
patients than in healthy control subjects [35]. Of the most interest, PTX3 was elevated in SSc patients who had digital ulcers or PAH, while FGF-2 was reduced in SSc patients with PAH. Multivariate analysis identified elevated PTX3 as an independent parameter associated with the presence of $\mathrm{DU}$ and $\mathrm{PAH}$. Furthermore, PTX3 levels were a useful predictor of future occurrences of digital ulcers and reduced FGF-2 was independently associated with the presence of PAH.

Chemokine CXCL4 levels have been found to be correlated with skin and lung fibrosis and also with pulmonary arterial hypertension. No data were provided regarding DU. But among chemokines, only CXCL4 predicted the risk and progression of systemic sclerosis [36].

Using a cohort of 100 patients and a follow-up of 3 years, vascular biomarkers of new events were investigated, primarily to predict the development of new DU that occurred in 17 SSc patients. Both angiogenic and vasculogenic markers were measured. Using various multivariable models, first the history of previous DU but also placenta growth factor (PIGF) levels and endothelial progenitor cell count were independent predictors of the development of DU [37]. The prediction of other cardiovascular end-points were studied suggesting stimulating clues with these markers but the number of events was low which limited statistical power. Interestingly, another study confirmed the promise of PIGF and also of Flit1 as measures of pulmonary hypertension in SSc [38].

Angiotensin II Type 1 receptor (AT1R) and endothelin 1 Type A receptor (ETAR) are functional autoantibodies directed against vascular receptors. A majority of SSC patients have increased levels of anti-AT $T_{1}$ and anti-ETAR antibodies compared to healthy donors. Moreover, in SSc patients, the auto-antibodies are associated with various vascular symptoms of the disease such as $\mathrm{PAH}$, DUs, and renal crisis. 
Nevertheless, the antibodies are also associated with the diffuse cutaneous subtype as well as with lung fibrosis. Altogether, these data suggest a possible role of the antibodies in disease mechanisms but their use in clinical practice for predicting damages remains to be established. In the context of $\mathrm{DU}$, it has been shown that anti-ETAR autoantibodies can be used together with the presence of current or past DU to identify patients with SSc who are at risk for the development of subsequent DU $[39,40]$.

Imaging may also provide some tools to predict DU and vascular outcomes. Few studies have been performed so far but capillaroscopy was found to be an interesting candidate and a prospective study of 6 months identified that the mean number of capillaries per millimeter in the middle finger of the dominant hand, the number of DU at enrolment, and the presence of critical digital ischemia at enrolment were risk factors for the development of new DUs. Other cardiovascular outcomes were not measured on that duration [41].

The carotid-femoral pulse wave velocity (PWV) is a marker of aortic stiffness that holds prognostic significance in various vascular conditions, including systemic hypertension, renal failure and heart failure. The augmentation index (Aix_75), defined as the amplitude of the reflected wave from the periphery to the heart, can be measured by applanation tonometry and depends on several factors including large artery but also medium and small arteries stiffness. Radial applanation tonometry has been investigated in a group of $63 \mathrm{SSc}$ patients to look for an association of PWV or Aix_75 with DU in 10 SSc patients. No differences existed in baseline characteristics between SSc-DU versus SSc-non DU patients, regarding cutaneous subset of the disease and disease duration, renal and pulmonary function, cardiovascular risk factors, heart function and pulmonary artery pressure [42]. SSc patients with DU 
versus those without had increased Aix_75 while there was no difference in PWV. The results of the multivariate logistic regression revealed that age, sex, erythrocyte sedimentation rate, aortic pulse pressure and DU were independently associated with Aix_75 [42]. Collectively these results suggest the existence of increased small and medium arteries stiffness in SSc patients with DU without significant aortic increased stiffness, when compared to SSc patients without DU. The predictive value of such tool on broader cardiovascular outcomes and in a larger population would be of interest.

\section{CONCLUSION}

Vascular injury and subsequent vascular dysfunction are among the earliest alterations in SSc and are considered to act within the initiating steps in SSc pathogenesis. Microcirculation impairment is the hallmark of the disease may also spread to larger vessels even if the reality of increased prevalence of atherosclerosis in SSc remains controversial. The process is undoubtedly generalized and all microvascular territories are affected. This is strongly supported by autopsy studies that showed lung and kidney vessels involvement despite the lack of any evidence of organ involvement [43]. Among all vascular complications, it is well known that DU are the most common clinical expression of an advanced vasculopathy. It remains unclear why this area is mostly affected although the permanent exposure to external stress might contribute to its severity. Some have speculated that DU could be a clinical marker of tissue damage (vascular and fibrotic changes), but the epidemiological studies do not clearly and reproducibly demonstrate a strong link between DU and other vascular complications. Indeed, cross-sectional studies show that SSc-DU patients have a more severe disease but there is no demonstration of 
higher frequency of PAH or renal crisis. The longitudinal studies further support poorer outcomes of SSc-DU patients and some do suggest some predictive value of baseline DU for subsequent DU or even PAH or overall cardio-vascular complications. However, at the moment, several methodological issues preclude firm conclusion. Indeed, the definition of the events differs between the studies, the time of observation is usually not very long for PAH which is usually a late complication and because of the scarcity of major cardiovascular events, the sample size may be an issue.

Biomarker studies highlight the systemic component of vasculopathy and suggest some links between DU and PAH but it seems that additional further and potential regional factors might contribute to more severe remodelling in the fingers or in the lung or in the kidney. Auto-antibodies might contribute to these specificities and it is of interest to see that DU are more common in dcSSc and probably antitopoisomerase positive patients whereas anti-centromere antibodies are reproducibly found in SSc-PAH patients and that anti-RNA polymerase 3 antibodies are strong markers of renal crisis. The role of others and functional antibodies are interesting clues in this context.

Regarding vascular SSc therapies, several PAH drugs are available in SSc-PAH but the drugs are given to patients who have already developed histologically very advanced vasculopathy. At a less severe stage, calcium channel blockers and iloprost are licenced for severe Raynaud's and bosentan for the prevention of DU. Clinical trials have shown their respective beneficial effects but the duration of the trials are short with a relative small number of selected patients and therefore, effects on other vascular outcomes could not be reliably measured. Scarce data are available from long-term observational studies but few did suggest that long-term use 
of iloprost may reduce vascular progression [44, 45] and that long-term use of calcium channel blockers could reduce heart or kidney progression [46, 47]. Although such results could support a continuum in the vasculopathy, these data are very preliminary and cannot allow any definite conclusion.

One might also add that the natural course of vasculopathy and its complications are moving in the recent years and the recent findings about DU recurrence showing faster healing and less relapse should stimulate further studies to assess vascular outcomes and management [48-50]. Therefore, SSc-DU patients have worse outcomes than non-affected patients and they should be managed as patients having a severe form of the disease [51]. However, the reason why vasculopathy may be mainly expressed in digital arteries in some patients and in pulmonary or kidney arteries in others remain unclear. Improving the knowledge in the field would distress this part of the disease that is a huge contributor to excessive morbidity and mortality. 
Table 1: Digital ulcer associations through multivariable analyses in large multicentre series of SSc patients (cross-sectional studies)

\begin{tabular}{|c|c|c|c|c|}
\hline Variable & $\begin{array}{c}\text { ItinerAIR-SSc } \\
(2009) \\
(n=599 \\
\text { patients })\end{array}$ & $\begin{array}{c}\text { German } \\
\text { network }(2009) \\
(n=1690)\end{array}$ & $\begin{array}{c}\text { Canadian } \\
\text { network } \\
(2011) \\
(n=938)\end{array}$ & $\begin{array}{c}\text { Spanish } \\
\text { registry } \\
(2016) \\
(n=1326)\end{array}$ \\
\hline $\begin{array}{l}\text { Definition of DU } \\
\text { (and prevalence) }\end{array}$ & $\begin{array}{c}\text { Prior or current } \\
\text { DU } \\
(53 \%)\end{array}$ & $\begin{array}{l}\text { Active DU at } \\
\text { inclusion } \\
(24 \%)\end{array}$ & $\begin{array}{c}\text { Past or } \\
\text { present DU } \\
(44 \%)\end{array}$ & $\begin{array}{l}\text { Prior or current } \\
\text { DU }(42 \%)\end{array}$ \\
\hline Age & + & - & + & + \\
\hline Male sex & + & ++ & - & - \\
\hline Smoking & - & Not studied & - & - \\
\hline Disease duration & + & - & - & - \\
\hline $\begin{array}{l}\text { Severe skin } \\
\text { involvement }\end{array}$ & + & NA & $\begin{array}{c}+ \text { (finger } \\
\text { mRSS) }\end{array}$ & - \\
\hline DcSSc & - & - & - & + \\
\hline $\begin{array}{l}\text { Anti- } \\
\text { topoisomerase }\end{array}$ & - & + & - & - \\
\hline $\begin{array}{l}\text { Erythrocyte } \\
\text { sedimentation rate }\end{array}$ & Not studied & + & - & Not studied \\
\hline $\begin{array}{l}\text { Esophageal } \\
\text { involvement }\end{array}$ & Not studied & + & $+/-$ & Not studied \\
\hline DLCO & $\begin{array}{c}+ \\
(<60 \%) \\
\end{array}$ & NA & - & - \\
\hline $\begin{array}{l}\text { Interstitial lung } \\
\text { disease }\end{array}$ & $\begin{array}{l}\text { (severe ILD is } \\
\text { and exclusion } \\
\text { criteria) }\end{array}$ & - & + & + \\
\hline $\begin{array}{l}\text { Pulmonary } \\
\text { hypertension }\end{array}$ & $\begin{array}{l}\text { (exclusion } \\
\text { criteria) }\end{array}$ & + & - & - \\
\hline Renal crisis & - & - & - & - \\
\hline HAQ score & Not studied & Not studied & + & Not studied \\
\hline
\end{tabular}


Figure 1: Sources of information to answer the research question about the relationships between digital ulceration and other SSc vascular complications.

References:

1. Elhai M, Avouac J, Kahan A, Allanore Y. Systemic sclerosis: Recent insights. Joint Bone Spine. 2015;82:148-53

2. Denton CP, Khanna D. Systemic sclerosis. Lancet. 2017 Apr 13. pii: S01406736(17)30933-9. doi: 10.1016/S0140-6736(17)30933-9.

3. Elhai M, Meune C, Boubaya M, Avouac J, Hachulla E, Balbir-Gurman A, Mapping and predicting mortality from systemic sclerosis. Ann Rheum Dis. 2017 Aug 23. pii: annrheumdis-2017-211448. doi: 10.1136/annrheumdis-2017-211448. [Epub ahead of print]

4. Matucci-Cerinic M, Kahaleh B, Wigley FM. Review: evidence that systemic sclerosis is a vascular disease. Arthritis Rheum. 2013;65:1953-62

5. Asano Y, Sato S. Vasculopathy in scleroderma. Semin Immunopathol. 2015;37:489-500.

6. Au K, Singh MK, Bodukam V, Bae S, Maranian P, Ogawa R, et al. Atherosclerosis in systemic sclerosis: a systematic review and metaanalysis. Arthritis Rheum 2011;63:2078-90.

7. Allanore $\mathrm{Y}$, Meune $\mathrm{C}$. Primary myocardial involvement in systemic sclerosis: evidence for a microvascular origin. Clin Exp Rheumatol. 2010;28(5 Suppl 62):S48-53

8. Silva I, Loureiro T, Teixeira A, Almeida I, Mansilha A, Vasconcelos C, et al. Digital ulcers in systemic sclerosis: role of flow-mediated dilatation and capillaroscopy as risk assessment tools. Eur J Dermatol. 2015;25:444-51

9. Manetti M, Romano E, Rosa I, Guiducci S, Bellando-Randone S, et al. Endothelial-to-mesenchymal transition contributes to endothelial dysfunction and dermal fibrosis in systemic sclerosis. Ann Rheum Dis. 2017;76:924-934

10. Avouac J, Vallucci M, Smith V, Senet P, Ruiz B, Sulli A, et al. Correlations between angiogenic factors and capillaroscopic patterns in systemic sclerosis. Arthritis Res Ther. 2013;15:R55

11. Manetti M, Guiducci S, Romano E, Avouac J, Rosa I, Ruiz B, et al. Decreased expression of the endothelial cell-derived factor EGFL7 in systemic sclerosis: potential contribution to impaired angiogenesis and vasculogenesis. Arthritis Res Ther. 2013;15:R165. 
12. Bellando Randone S, George J, Mazzotta C, Guiducci S, Furst DE, et al. Angiostatic and angiogenic chemokines in systemic sclerosis: an overview $J$ scleroderma relat disord 2017:2:1-10

13. Maurer B, Distler A, Suliman YA, Gay RE, Michel BA, Gay S, et al. Vascular endothelial growth factor aggravates fibrosis and vasculopathy in experimental models of systemic sclerosis. Ann Rheum Dis. 2014;73:1880-7.

14. Derrett-Smith EC, Dooley A, Gilbane AJ, Trinder SL, Khan K, Baliga R, et al. Endothelial injury in a transforming growth factor $\beta$-dependent mouse model of scleroderma induces pulmonary arterial hypertension. Arthritis Rheum. 2013;65:2928-39.

15. Avouac J, Wipff J, Goldman O, Ruiz B, Couraud PO, Chiocchia G, et al. Angiogenesis in systemic sclerosis: impaired expression of vascular endothelial growth factor receptor 1 in endothelial progenitor-derived cells under hypoxic conditions. Arthritis Rheum. 2008;58:3550-61

16. Matucci-Cerinic M, Pietrini U, Marabini S. Local venomotor response to intravenous infusion of substance $\mathrm{P}$ and glyceryl trinitrate in systemic sclerosis. Clin Exp Rheumatol. 1990;8:561-5

17. Suliman YA, Distler O. Novel Aspects in the Pathophysiology of Peripheral Vasculopathy in Systemic Sclerosis. Curr Rheumatol Rev. 2013;9:237-44

18. Chora I, Romano E, Manetti M, Mazzotta C, Costa R, Machado V, et al. Evidence for a Derangement of the Microvascular System in Patients with a Very Early Diagnosis of Systemic Sclerosis. J Rheumatol. 2017;44:1190-1197

19. Hofstee HM, Voskuyl AE, Vonk Noordegraaf A, Smulders YM, Postmus PE, Dijkmans BA, et al. Pulmonary arterial hypertension in systemic sclerosis is associated with profound impairment of microvascular endothelium-dependent vasodilatation. J Rheumatol. 2012;39:100-5.

20. Takahashi T, Asano Y, Amiya E, Hatano M, Tamaki Z, Takata M, et al. Clinical correlation of brachial artery flow-mediated dilation in patients with systemic sclerosis. Mod Rheumatol. 2014;24:106-11

21. Tiev KP, Diot E, Clerson P, Dupuis-Siméon F, Hachulla E, Hatron PY, et al. Clinical features of scleroderma patients with or without prior or current ischemic digital ulcers: post-hoc analysis of a nationwide multicenter cohort (ItinérAIR-Sclérodermie). J Rheumatol. 2009;36:1470-6.

22. Sunderkötter C, Herrgott I, Brückner C, Moinzadeh P, Pfeiffer C, Gerss J, et al. Comparison of patients with and without digital ulcers in systemic sclerosis: detection of possible risk factors. Br J Dermatol. 2009;160:835-43

23. Tolosa-Vilella C, Morera-Morales ML, Simeón-Aznar CP, Marí-Alfonso B, Colunga-Arguelles D, Callejas Rubio JL, et al. Digital ulcers and cutaneous subsets of systemic sclerosis: Clinical, immunological, nailfold capillaroscopy, and survival differences in the Spanish RESCLE Registry. Semin Arthritis Rheum. 2016;46:200-8.

24. Khimdas S, Harding S, Bonner A, Zummer B, Baron M, Pope J; Canadian Scleroderma Research Group. Associations with digital ulcers in a large cohort of systemic sclerosis: results from the Canadian Scleroderma Research Group registry. Arthritis Care Res (Hoboken). 2011;63:142-9

25. Motegi S, Toki S, Hattori T, Yamada K, Uchiyama A, Ishikawa O. No association of atherosclerosis with digital ulcers in Japanese patients with systemic sclerosis: evaluation of carotid intima-media thickness and plaque characteristics. $J$ Dermatol. 2014;41:604-8 
26. Hurabielle C, Avouac J, Lepri G, de Risi T, Kahan A, Allanore Y. Skin telangiectasia identify a subset of Systemic Sclerosis patients with severe vascular disease. Arthritis Care Res (Hoboken). 2016;68:1021-7.

27. Shah AA, Wigley FM, Hummers LK. Telangiectases in scleroderma: a potential clinical marker of pulmonary arterial hypertension. J Rheumatol. 2010;37:98-104

28. Woodworth TG, Suliman YA, Furst DE, Clements P. Scleroderma renal crisis and renal involvement in systemic sclerosis. Nat Rev Nephrol. 2016;12:678-691.

29. Hachulla E, Clerson P, Launay D, Lambert M, Morell-Dubois S, Queyrel V, et al. Natural history of ischemic digital ulcers in systemic sclerosis: single-center retrospective longitudinal study. J Rheumatol. 2007;34:2423-30.

30. Steen V, Medsger TA Jr. Predictors of isolated pulmonary hypertension in patients with systemic sclerosis and limited cutaneous involvement. Arthritis Rheum. 2003;48:516-22.

31. Mihai C, Landewé R, van der Heijde D, Walker UA, Constantin PI, Gherghe AM, et al, and EUSTAR co-authors. Digital ulcers predict a worse disease course in patients with systemic sclerosis. Ann Rheum Dis. 2016;75:681-6.

32. Morrisroe K, Stevens W, Sahhar J, Rabusa C, Nikpour M, Proudman S; Australian Scleroderma Interest Group (ASIG). Epidemiology and disease characteristics of systemic sclerosis-related pulmonary arterial hypertension: results from a real-life screening programme. Arthritis Res Ther. 2017;19:42.

33. Hunzelmann N, Riemekasten G, Becker MO, Moinzadeh P, Kreuter A, Melchers I, et al. The Predict Study: low risk for digital ulcer development in patients with systemic sclerosis with increasing disease duration and lack of topoisomerase-1 antibodies. Br J Dermatol. 2016;174:1384-7

34. Chora I, Guiducci S, Manetti M, Romano E, Mazzotta C, Bellando-Randone S, et al. Vascular biomarkers and correlation with peripheral vasculopathy in systemic sclerosis. Autoimmun Rev. 2015;14:314-22.

35. Shirai Y, Okazaki Y, Inoue Y, Tamura Y, Yasuoka H, Takeuchi T, et al. Elevated levels of pentraxin 3 in systemic sclerosis: associations with vascular manifestations and defective vasculogenesis. Arthritis Rheumatol. 2015;67:498507.

36. van Bon L, Affandi AJ, Broen J, Christmann RB, Marijnissen RJ, Stawski L, et al. Proteome-wide analysis and CXCL4 as a biomarker in systemic sclerosis. $N$ Engl J Med. 2014;370:433-43

37. Avouac J, Meune C, Ruiz B, Couraud PO, Uzan G, Boileau C, et al. Angiogenic biomarkers predict the occurrence of digital ulcers in systemic sclerosis. Ann Rheum Dis. 2012;71:394-9.

38. McMahan Z, Schoenhoff F, Van Eyk JE, Wigley FM, ummers LK. Biomarkers of pulmonary hypertension in patients with scleroderma: a case-control study. Arthritis Res Ther. 2015;17:201.

39. Cabral-Marques O, Riemekasten G. Vascular hypothesis revisited: Role of stimulating antibodies against angiotensin and endothelin receptors in the pathogenesis of systemic sclerosis. Autoimmun Rev. 2016;15:690-4.

40. Avouac J, Riemekasten G, Meune C, Ruiz B, Kahan A, Allanore Y. Autoantibodies against Endothelin 1 Type A Receptor Are Strong Predictors of Digital Ulcers in Systemic Sclerosis. J Rheumatol. 2015;42:1801-7.

41. Cutolo M, Herrick AL, Distler O, Becker MO, Beltran E, Carpentier P, et al. Nailfold Videocapillaroscopic Features and Other Clinical Risk Factors for Digital Ulcers in Systemic Sclerosis: A Multicenter, Prospective Cohort Study. Arthritis Rheumatol. 2016;68:2527-39. 
42. Aïssou L, Meune C, Avouac J, Meunier M, Elhaï M, Sorbets E, et al. Small, medium but not large arteries are involved in digital ulcers associated with systemic sclerosis. Joint Bone Spine. 2016;83:444-7.

43. D'Angelo WA, Fries JF, Masi AT, Shulman LE. Pathologic observations in systemic sclerosis (scleroderma). A study of fifty-eight autopsy cases and fiftyeight matched controls. Am J Med. 1969;46:428-40.

44. Airò P, Rossi M, Scarsi M, Danieli E, Grottolo A, Zambruni A et al. Diseasemodifying effects of long-term cyclic iloprost therapy in systemic sclerosis. A retrospective analysis and comparison with a control group. Clin Exp Rheumatol. 2007;25:722-7.

45. Caramaschi P, Dalla Gassa A, Prati D, Barausse G, Tinazzi I, Ravagnani V, et al. Severe vascular complications in patients affected by systemic sclerosis cyclically treated with iloprost. Rheumatol Int. 2012;32:1933-8.

46. Allanore Y, Meune C, Vonk MC, Airo P, Hachulla E, Caramaschi P, et al. Prevalence and factors associated with left ventricular dysfunction in the EULAR Scleroderma Trial and Research group (EUSTAR) database of patients with systemic sclerosis. Ann Rheum Dis. 2010;69:218-21

47. Montanelli G, Beretta L, Santaniello A, Scorza R. Effect of dihydropyridine calcium channel blockers and glucocorticoids on the prevention and development of scleroderma renal crisis in an Italian case series. Clin Exp Rheumatol. 2013;31(2 Suppl 76):135-9.

48. Khanna D, Denton CP, Merkel PA, Krieg T, Le Brun FO, Marr A, et al. Effect of Macitentan on the Development of New Ischemic Digital Ulcers in Patients With Systemic Sclerosis: DUAL-1 and DUAL-2 Randomized Clinical Trials. JAMA. 2016;315:1975-88.

49. Hachulla E, Hatron PY, Carpentier P, Agard C, Chatelus E, Jego P, et al. Ann Rheum Dis. 2016;75:1009-15

50. Suliman YA, Bruni C, Jonhson SR, Praino E, Alemam M, Borazan N, et al. Defining skin ulcers in systemic sclerosis: systematic literature review and proposed World Scleroderma Foundation (WSF) definition. J scleroderma relat disord 2017;2:115-120

51. Hughes M, Ong VH, Anderson ME, Hall F, Moinzadeh P, Griffiths B, et al. Consensus best practice pathway of the UK Scleroderma Study Group: digital vasculopathy in systemic sclerosis. Rheumatology (Oxford). 2015;54:2015-24. 